\title{
Tracking Nanoparticle Uptake in a Spontaneous and Immunocompetent Woodchuck Liver Cancer Model
}

AUTHOR NAMES

Lewis Y. Liu ${ }^{1,2}$, Xue-Zhong Ma ${ }^{1}$, Ben Ouyang ${ }^{3}$, Danielle P. Ings ${ }^{4}$, Sagar Marwah ${ }^{1}$, Jeff Liu ${ }^{5}$, Annie Y. Chen $^{4}$, Rahul Gupta ${ }^{1}$, Justin Manuel ${ }^{1}$, Xu-Chun Chen ${ }^{1}$, Blair K. Gage ${ }^{1,6}$, Iulia Cirlan ${ }^{7}$, Nicholas Khuu ${ }^{7}$, Sai Chung ${ }^{1,2}$, Damra Camat ${ }^{1,2}$, Michael Cheng ${ }^{1,8}$, Manmeet Sekhon ${ }^{1}$, Kyryl Zagorovsky ${ }^{3,8}$, Mohamed A. Abdou Mohamed ${ }^{8,9}$, Cornelia Thoeni ${ }^{1}$, Jawairia Atif ${ }^{1,2}$, Juan Echeverri ${ }^{1}$, Dagmar Kollmann ${ }^{1}$, Sandra Fischer $^{1,8}$, Gary D. Bader ${ }^{5}$, Warren C.W. Chan ${ }^{3,9}$, Tomasz I. Michalak ${ }^{* 4}$, Ian D. McGilvray*1, Sonya A. MacParland ${ }^{* 1,2,8}$ (*co-senior to whom correspondence should be addressed)

\section{AUTHOR ADDRESS}

\footnotetext{
${ }^{1}$ Soham \& Shaila Ajmera Family Transplant Centre, Toronto General Research Institute, University Health Network, 200 Elizabeth Street, Toronto, Ontario, Canada, M5G 2C4

${ }^{2}$ Department of Immunology, University of Toronto, Medical Sciences Building, Room 6271, 1 King's College Circle, Toronto, Ontario, Canada, M5S 1A8

${ }^{3}$ Institute of Biomaterials and Biomedical Engineering, University of Toronto, Rosebrugh Building, Room 407, 164 College Street, Toronto, Ontario, Canada, M5S 3G9

${ }^{4}$ Molecular Virology and Hepatology Research Group, Faculty of Medicine, Health Sciences Centre, Memorial University, 300 Prince Philip Drive, St. John's, Newfoundland, Canada, A1B 3V6

${ }^{5}$ Terrence Donnelly Centre for Cellular and Biomolecular Research, University of Toronto, 160 College Street, Room 230, Toronto, Ontario, Canada, M5S 3E1

${ }^{6}$ McEwen Stem Cell Institute, University Health Network, Toronto, ON, Canada, M5G 1L7

${ }^{7}$ Princess Margaret Genomics Centre, University Health Network, Toronto, Ontario, M5G 1L7

${ }^{8}$ Luna Nanotech, 439 University Avenue, $5^{\text {th }}$ Floor, Toronto, Ontario, Canada, M5G 1Y8

${ }^{9}$ Botany and Microbiology Department, Faculty of Science, Zagazig University, Zagazig, Egypt, 44519

${ }^{10}$ Department of Laboratory Medicine and Pathobiology, University of Toronto, Medical Sciences Building, Room 6271, 1 King's College Circle, Toronto, Ontario, Canada, M5S 1A8

${ }^{11}$ Department of Materials Science and Engineering, University of Toronto, 160 College Street, Room 450, Toronto, Ontario, Canada, M5S 3E1
} 


\section{Table of Contents}

Figure S1: Comparison of animal tumor models.

Figure S2: Characterization of quenching factor of the IR750 dye immobilized on the surface of 60-nm in diameter gold nanoparticles....

Figure S3: Percent CD14 ${ }^{+}$cells that took up NPs identified in multiple organs in are shown for all four experiments in which NPs distribution was examined at $12 \mathrm{~h}$ p.i. 5

Figure S4: In vivo distribution of NPs at 48 hours after their intravenous injection 6

Figure S5: Comparison of histological characteristics of WHV-positive, HCC-bearing and healthy livers.

Figure S6: Scanning electron microscopy of healthy and WHV-chronically infected woodchuck livers 8

Figure S7: Sectioning of woodchuck HCC for analysis of NP distribution and overall view of a large HCC tumor in woodchuck chronically infected with WHV

Figure S8: Gating strategy of all $12 \mathrm{~h}$ p.i. in vivo NP uptake experiments in tumour 10

Figure S9: Gating strategy for cell sorting experiments 11

Figure S10: Characteristics of woodchucks investigated.

\section{List of Additional Supplementary Material}

Supplemental Video 1: Live confocal microscopy imagining.

Supplemental Information 1: Quality control for RNA-sequencing experiments.

Supplemental Table 1: Amino acid sequence alignment between woodchuck and human.

Supplemental Table 2: Gene expression values for FACS sorted cell populations. 


\begin{tabular}{|c|c|c|c|c|c|}
\hline \multicolumn{2}{|l|}{ Other models } & \multicolumn{3}{|c|}{ Drawbacks } & $\begin{array}{l}\text { How the woodchuck tumor model } \\
\text { circumvents these drawbacks }\end{array}$ \\
\hline \multicolumn{2}{|c|}{$\begin{array}{l}\text { Xenograft } \\
\text { (Orthotopic/Ectopic) } \\
\text { Mouse Xenograft Models } \\
\text { (Caviglia and Schwabe } \\
\text { 2015; Brown et al. 2018) }\end{array}$} & \multicolumn{3}{|c|}{$\begin{array}{l}\text { Mouse xenograft models - Immunocompromised } \\
\text { (no adaptive immunity), no viral infection. Loss of } \\
\text { resident tissue architecture and tumor niche } \\
\text { interactions in Ectopic and complicated surgery for } \\
\text { orthotopic }\end{array}$} & $\begin{array}{l}\text { Both adaptive and innate s\} } \\
\text { and intact tissue architectur } \\
\text { tumor development in its na } \\
\text { environment. }\end{array}$ \\
\hline \multicolumn{2}{|c|}{$\begin{array}{l}\text { Syngeneic } \\
\text { (Orthotopic/Ectopic) } \\
\text { Mouse transplant models } \\
\text { (Caviglia and Schwabe } \\
\text { 2015; Li et al. 2019) }\end{array}$} & \multicolumn{3}{|c|}{$\begin{array}{l}\text { Mouse syngeneic models - Immunocompetent but } \\
\text { transplantation of tumor into susceptible but } \\
\text { otherwise healthy mice results in loss of tissue } \\
\text { architecture and tumor niche interactions } \\
\text { VX2 Rabbit - tumors propagate in skeletal muscle } \\
\text { and can be transplanted onto the liver of recipient } \\
\text { rabbit however VX2 tumors are squamous cell } \\
\text { carcinomas which have different tissue origin than } \\
\text { HCC }\end{array}$} & $\begin{array}{l}\text { Tumor development occurs } \\
\text { due to WHV infection where } \\
\text { architecture and local tumo } \\
\text { preserved. }\end{array}$ \\
\hline \multicolumn{2}{|c|}{$\begin{array}{l}\text { Chemically Induced HCC } \\
\text { DEN-rat/mice (Gade et al. } \\
\text { 2015; Aleksic et al. 2011) }\end{array}$} & \multicolumn{3}{|c|}{$\begin{array}{l}\text { DEN-rat/mice - Not virally induced. Hard to } \\
\text { determine the clinical relevance of molecular } \\
\text { pathways involved in chemically vs viral-induced } \\
\text { HCC. } \\
\text { Morris - Aggressive metastatic behavior. Not virally } \\
\text { induced. } \\
\text { Novikoff - Low tumor induction rates with possibility } \\
\text { of spontaneous tumor regression. Not virally induced. }\end{array}$} & $\begin{array}{l}\text { WHV induced HCC recapit } \\
\text { induced HCC in humans } \mathrm{m} \\
\text { terms of tumor developmen } \\
\text { progression with respects } \mathrm{t} \\
\text { pathways activated and gro } \\
\text { pathology. }\end{array}$ \\
\hline \multicolumn{2}{|c|}{$\begin{array}{l}\text { Genetically Engineered } \\
\text { (Transgenic/Endogenous) } \\
\text { Genetically modified mice } \\
\text { (GEM) (Kim et al. 1991; } \\
\text { Sharpless et al. 2006) } \\
\text { Oncopig cancer model } \\
\text { (OCM) (Schook et al. } \\
\text { 2015; Shachtschneider et } \\
\text { al. 2017) }\end{array}$} & \multicolumn{3}{|c|}{$\begin{array}{l}\text { GEM- Viral infection is modeled by over expression of } \\
\text { tumor promoting factors like HBx gene but does not } \\
\text { include whole virus and therefore no replication and } \\
\text { further infection. Other mechanisms of } \\
\text { hepatocarcinogenesis like viral integration is left out. } \\
\text { Also hard to control the amount of gene product; may } \\
\text { not be physiologically relevant. } \\
\text { OCM- Overexpression of } 2 \text { oncogenes (KRAS and } \\
\text { TP53) does not capture the full repertoire of genetic } \\
\text { drivers of virus induced hepatocarcinogenesis. } \\
\text { Engraft tumors onto SCID mice } \\
\text { (Immunocompromised) or direct delivery of AdCre to } \\
\text { pig (tumor development depends on site of injection) } \\
\text { or cultured porcine hepatocytes (tissue architecture } \\
\text { lost). }\end{array}$} & $\begin{array}{l}\text { Complete wild-type virus ne } \\
\text { woodchucks and recapitula } \\
\text { infection, viral induced tum } \\
\text { and immune response to bc } \\
\text { tumor. } \\
\text { Tumor and tissue architect } \\
\text { its native environment. }\end{array}$ \\
\hline \multicolumn{6}{|l|}{ B } \\
\hline Species: & \multicolumn{2}{|c|}{ Human } & Woodchuck & Rat & Mouse \\
\hline $\begin{array}{l}\text { Average weight } \\
(\mathrm{kg})\end{array}$ & \multicolumn{2}{|c|}{70} & 4 & 0.5 & 0.03 \\
\hline $\begin{array}{l}\text { Percent of } \\
\text { human weight }\end{array}$ & \multicolumn{2}{|c|}{$100 \%$} & $5.7 \%$ & $0.007 \%$ & $0.0004 \%$ \\
\hline $\begin{array}{l}\text { Advantages of } \\
\text { large animal } \\
\text { models }\end{array}$ & \multicolumn{5}{|c|}{$\begin{array}{l}\text { 1. More tissue available for downstream experiments } \\
\text { 2. The larger native vasculature allows for a wider range of interventions to } \\
\text { be tested and validated, especially interventions that are used in } \\
\text { human. This is particularly significant because not only can the } \\
\text { woodchuck closely recapitulate human hepatitis virus induced liver } \\
\text { cancer, it can also be a platform to test the efficacy of the surgical } \\
\text { interventions that are commonly used to treat hepatic malignancies. }\end{array}$} \\
\hline
\end{tabular}

Figure S1: Comparison of animal tumor models. (Supports Figure 1A) (A) How the woodchuck animal system addresses key drawbacks of the currently available in vivo tumor models. (B) Comparison of average weights of human, woodchuck, rat and mouse including advantages of using large animal models. 


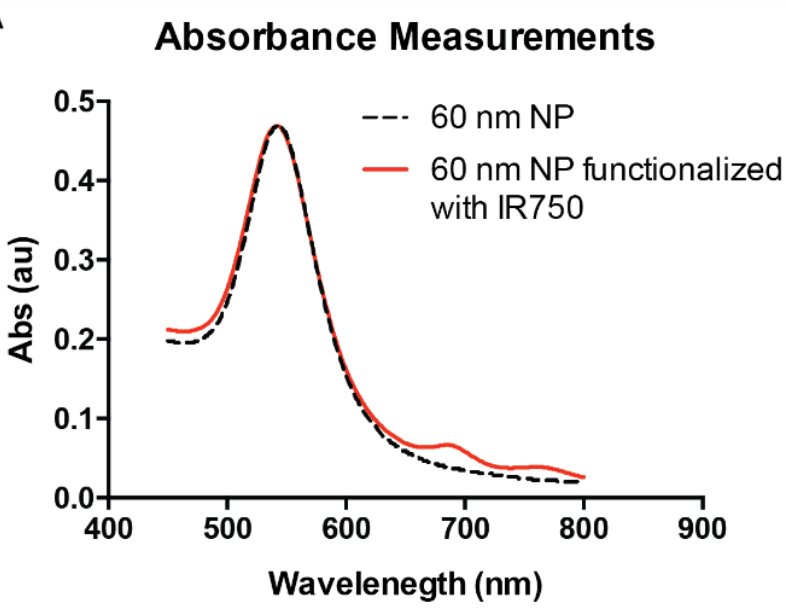

C

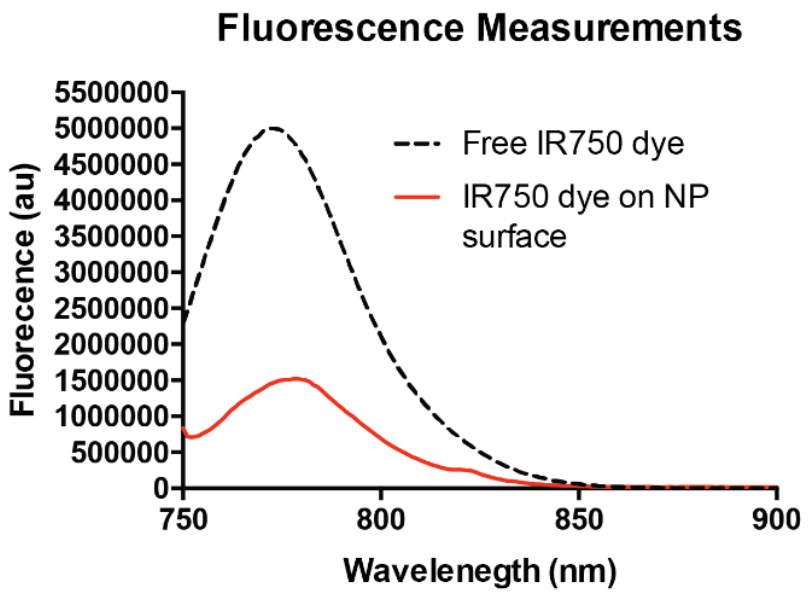

B

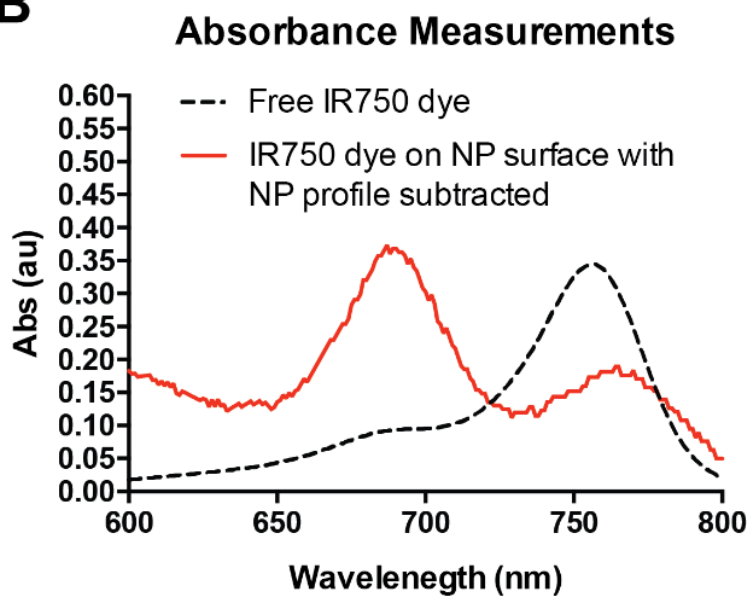

D

\begin{tabular}{|l|c|c|}
\hline & Free Dye & Dye on NP \\
\hline Abs@755nm (OD) & 1 & 1 \\
\hline Ex $\boldsymbol{\Lambda}(\mathbf{n m})$ & 740 & 740 \\
\hline Em $\boldsymbol{\Lambda}(\mathbf{n m})$ & $750-900$ & $750-900$ \\
\hline Peak Em (au) & $5.00 E+06$ & $1.45 E+06$ \\
\hline Quenching Factor & 1 & 0.29 \\
\hline
\end{tabular}

Figure S2: Characterization of quenching factor of the IR750 dye immobilized on the surface of 60-nm in diameter gold nanoparticles. (Supports Figure 2) (A) Comparison of the absorbance spectrum of unmodified nanoparticles to the spectrum of nanoparticles functionalized with IR750 dye. The dye contributes to the absorbance between 650 and $800 \mathrm{~nm}$. (B) Absorbance profile of IR750 functionalized nanoparticles from A subtracted from the absorbance profile of unmodified nanoparticles. The subtracted profile is compared to the absorbance profile of the free IR750 dye. Increase in the peak at $\sim 680 \mathrm{~nm}$ compared to the profile of the free dye indicates the formation of self-quenched nonfluorescence dye dimers when the dye is immobilized on the nanoparticle surface. The dimer formation is expected to reduce the overall fluorescence signal generated by the dye. (C) Fluorescence measurements of IR750 dye immobilized on the nanoparticle surface compared to that of the free IR750 dye. The concentration of IR750 dye functionalized nanoparticles was adjusted until the absorbance of $\sim 755 \mathrm{~nm}$ peak of the nanoparticle subtracted peak shown in B (which is generally used for the quantification of IR750 dye) was equal to the peak absorbance of the free dye. This way the concentration of free dye molecules was equal to the concentration of nanoparticle-immobilized molecules in their respective vials. Fluorescence measurements were performed one after another using Ex/Em $=740$ $\mathrm{nm} /(750 \mathrm{~nm}-900 \mathrm{~nm})$. (D) Table listing imaging parameters and peak emission values from C. Quenching factor was calculated by dividing the fluorescence signal obtained from the IR750 dye immobilized on the nanoparticle by the signal obtained from the free dye. The reduction of the dye fluorescence on the nanoparticle surface are largely the result of the formation of self-quenching dimers between multiple dye molecules closely positioned on the nanoparticle surface. 

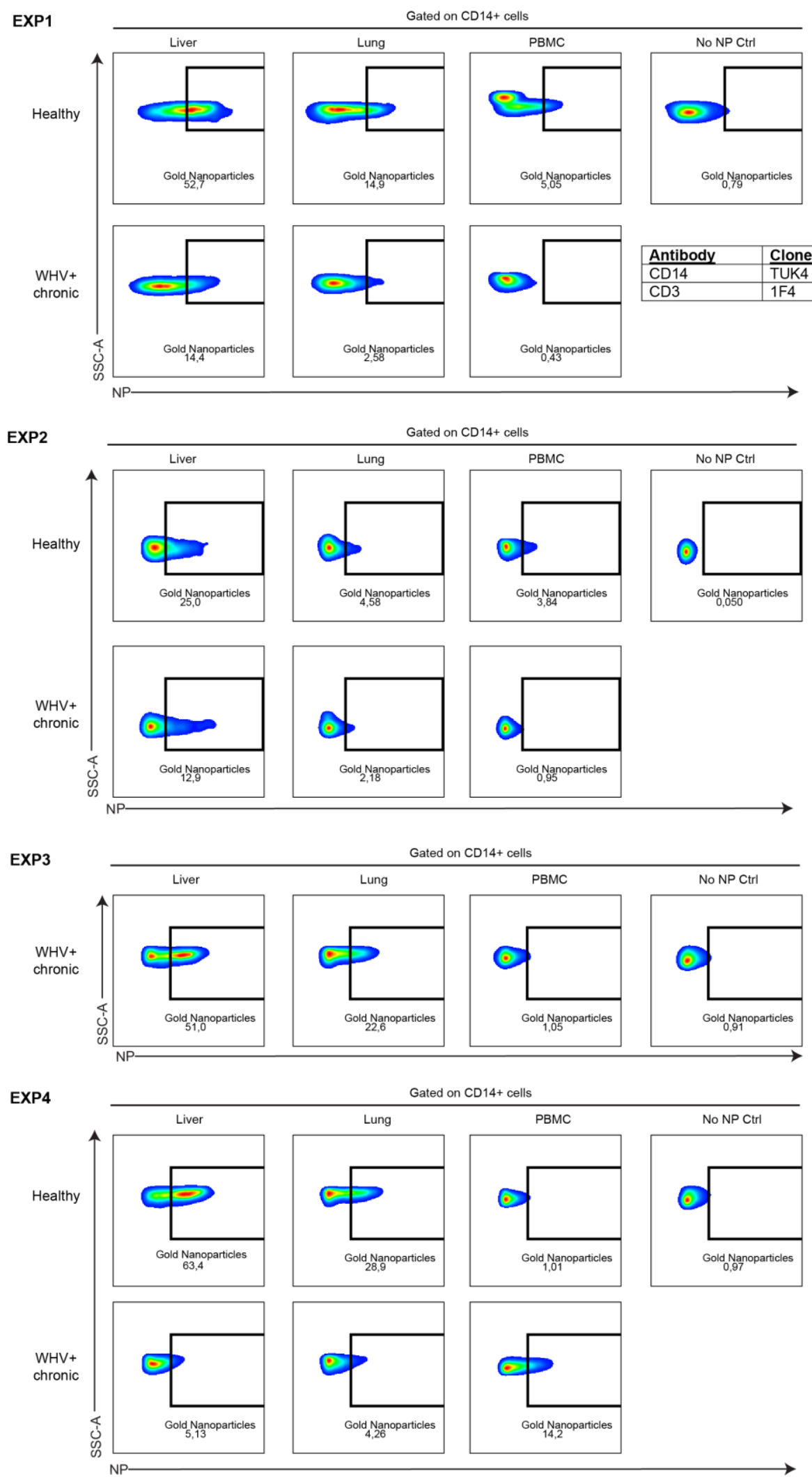

Figure S3: Percent $\mathrm{CD}^{+}$cells that took up NPs identified in multiple organs are shown for all four experiments in which NPs distribution was examined at 12 h p.i. (Supports Figure 3). Within each experiment, samples from liver, lung, PBMC from NP-injected animals and from controls not injected with NPs are shown (top labels) for healthy (top row) and chronically WHV-infected animals (bottom row). Please refer to Figure 3A for full gating strategy. Woodchuck cross-reactive antibodies used for flow cytometry and cell sorting experiments (table top right). 
A

i)
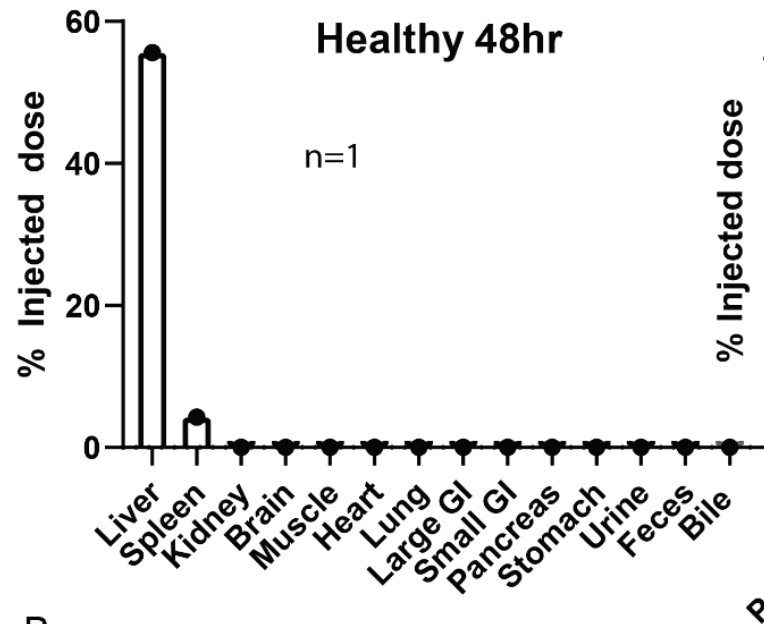

B

i)

ڤ્
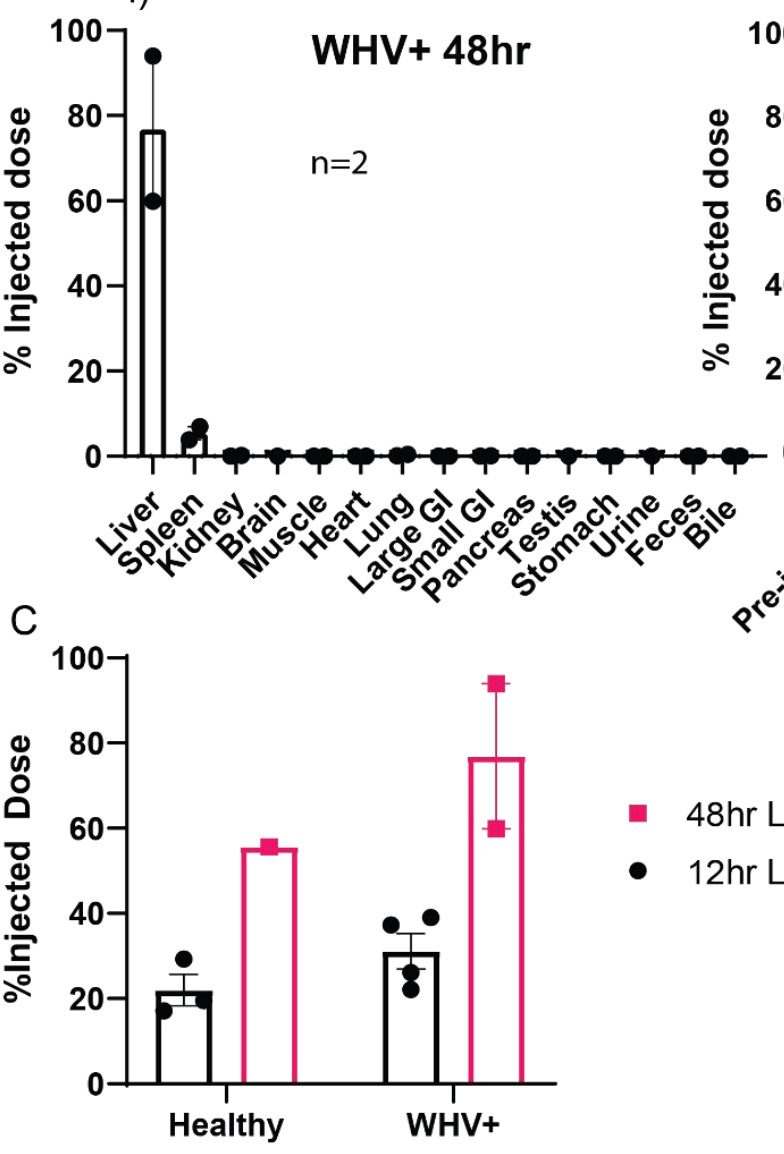

ii)
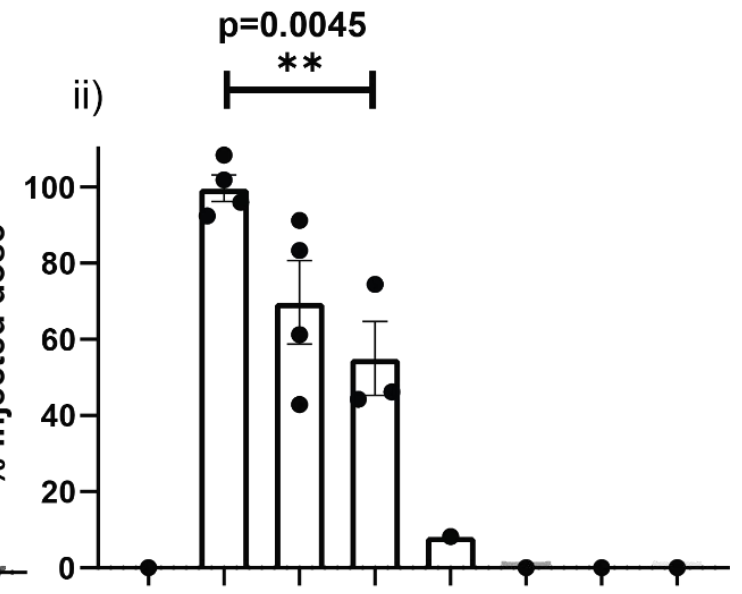

ii)

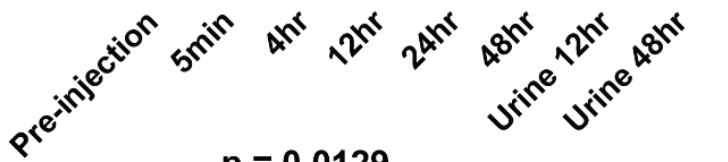

$\mathrm{p}=0.0129$

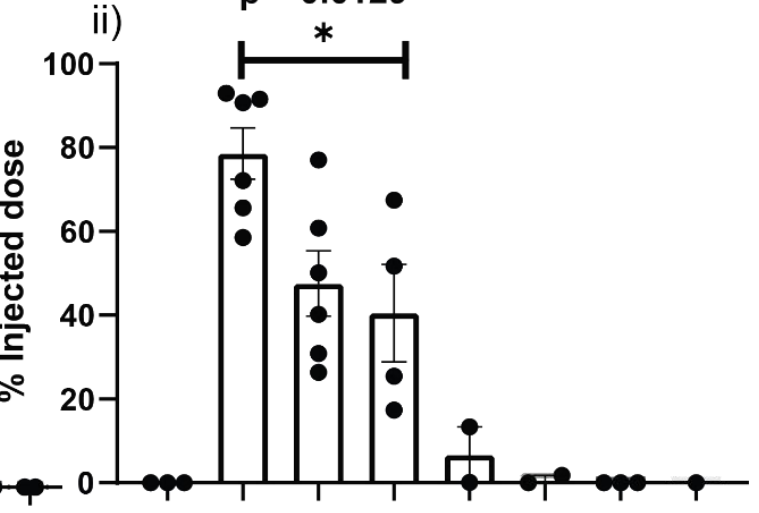

- 48hr Liver

- $12 \mathrm{hr}$ Liver

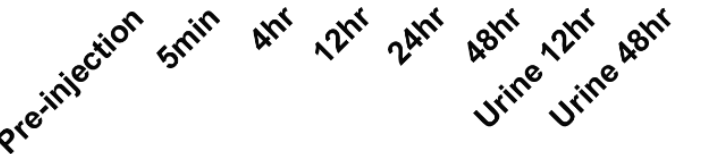

Figure S4: In vivo distribution of NPs at 48 hours after their intravenous injection (Supports Figure $3 B$ and C). (A) Percentage of injected dose of 60-nm gold NPs in each organ, as well as urine, feces, and bile at $48 \mathrm{~h}$ p.i. (i) and in blood at different time points and in urine at 12 and $48 \mathrm{~h}$ p.i. (ii) as measured by ICP-MS in a healthy animal. (B) Same analysis as in (A) but in two WHV-infected animals with HCC. (C) Comparison of the percentage of injected NP dose present in the liver (healthy and uninvolved tissue) at 12 and $48 \mathrm{~h}$ p.i. in healthy and WHV-positive animals. Error bars are representative of at least 2 replicates $+/$ - SEM. Statistical significance was evaluated using unpaired t test where $(*)<0.05$ and $(* *)<0.01$. 

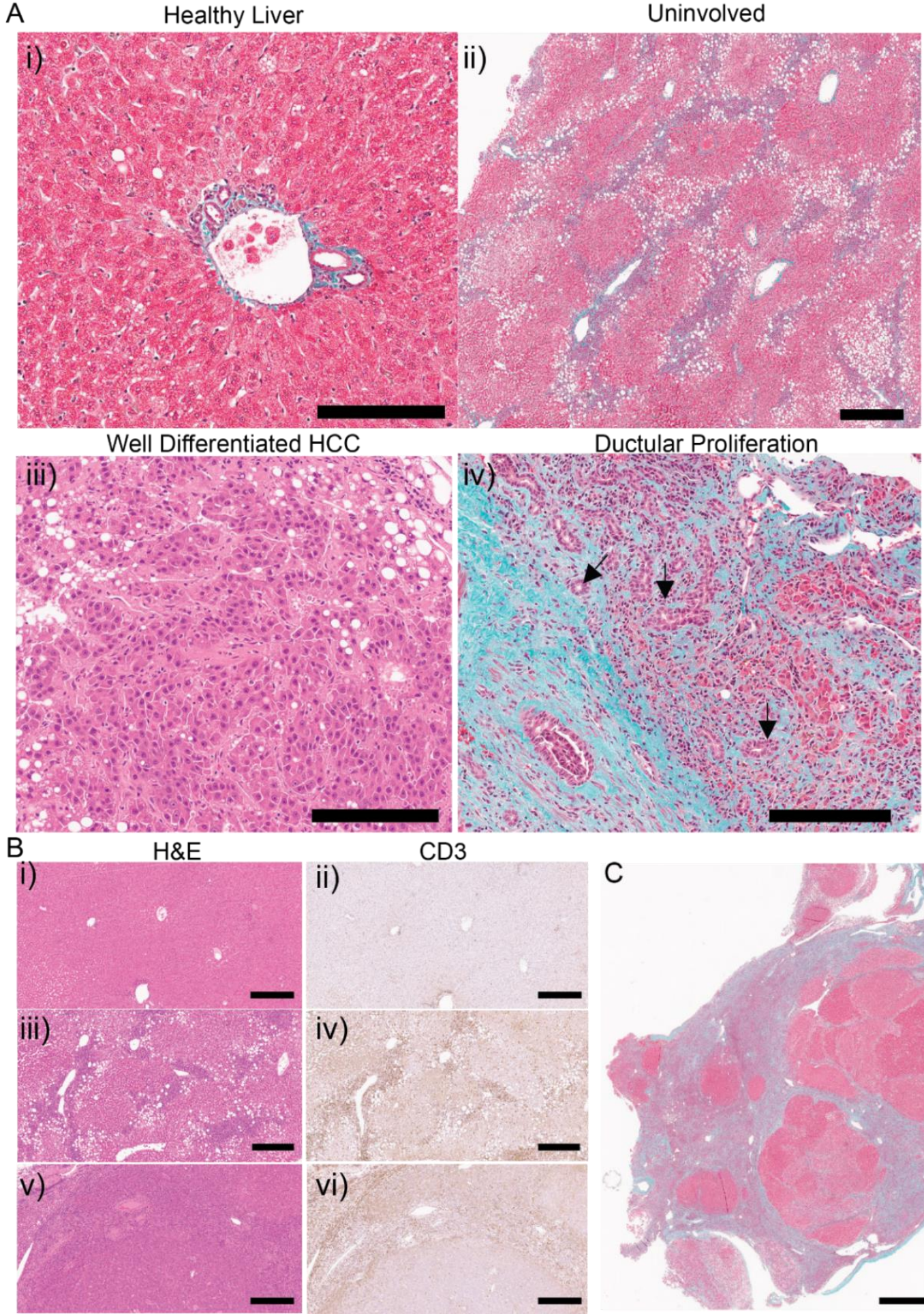

ii)

CD3

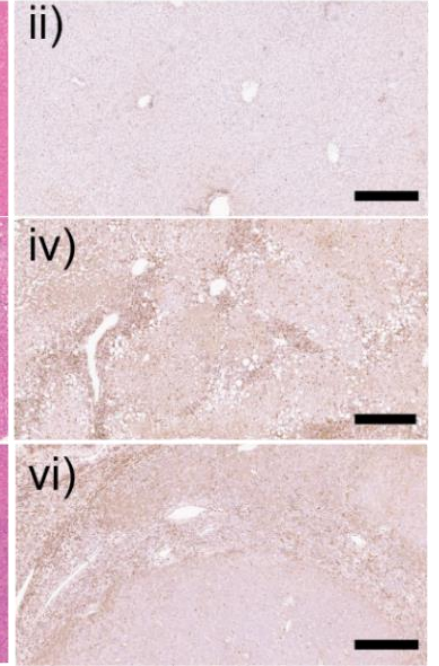

C

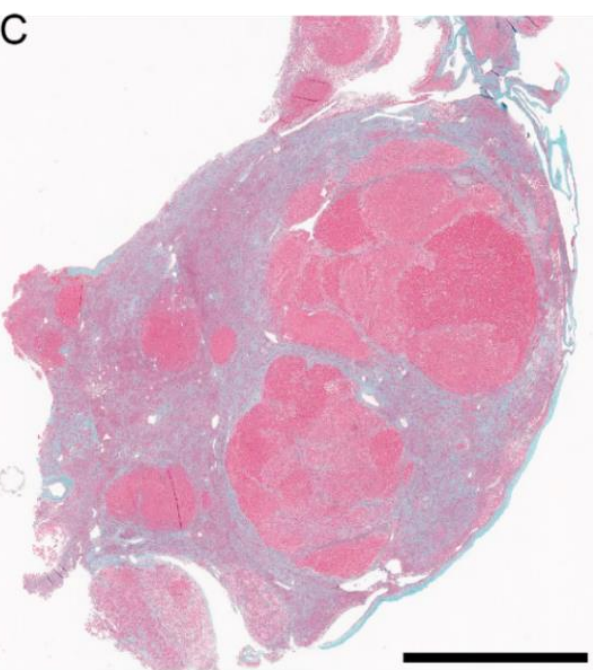

Figure S5: Comparison of histological characteristics of WHV-positive, HCC-bearing and healthy livers (Supports Figure 5). (A) Histology of i) healthy liver, ii) tumor-uninvolved chronically WHVinfected liver, iii) HCC, and iv) bile ducts proliferation which can be a hallmark of HCC. Sections were stained with Massons's trichrome (A.i, A.ii, and A.iv) or H\&E (A.iii). Scale bars in (A) are $200 \mu \mathrm{m}$ for (i, iii, iv) and $500 \mu \mathrm{m}$ for (ii). (B) Matched H\&E and imunohistochemical staining for CD3 in healthy liver (B.i and B.ii), tumor-uninvolved chronically infected liver (B.iii and B.iv), and a small HCC tumor (B.v and B.vi). All scale bars represent $300 \mu \mathrm{m}$. (C) Masson's trichrome stain of tumor core indicating the presence of a few tumorous nodules surrounded by bands of fibrotic tissue. Scale bar represents 4 $\mathrm{mm}$. Substantial steatosis seen in some chronically infected animals noticed in this study was a consequence of naturally occurring intrahepatocellular accumulation of fat droplets resolving after hibernation (Aii-iii and Biii). 


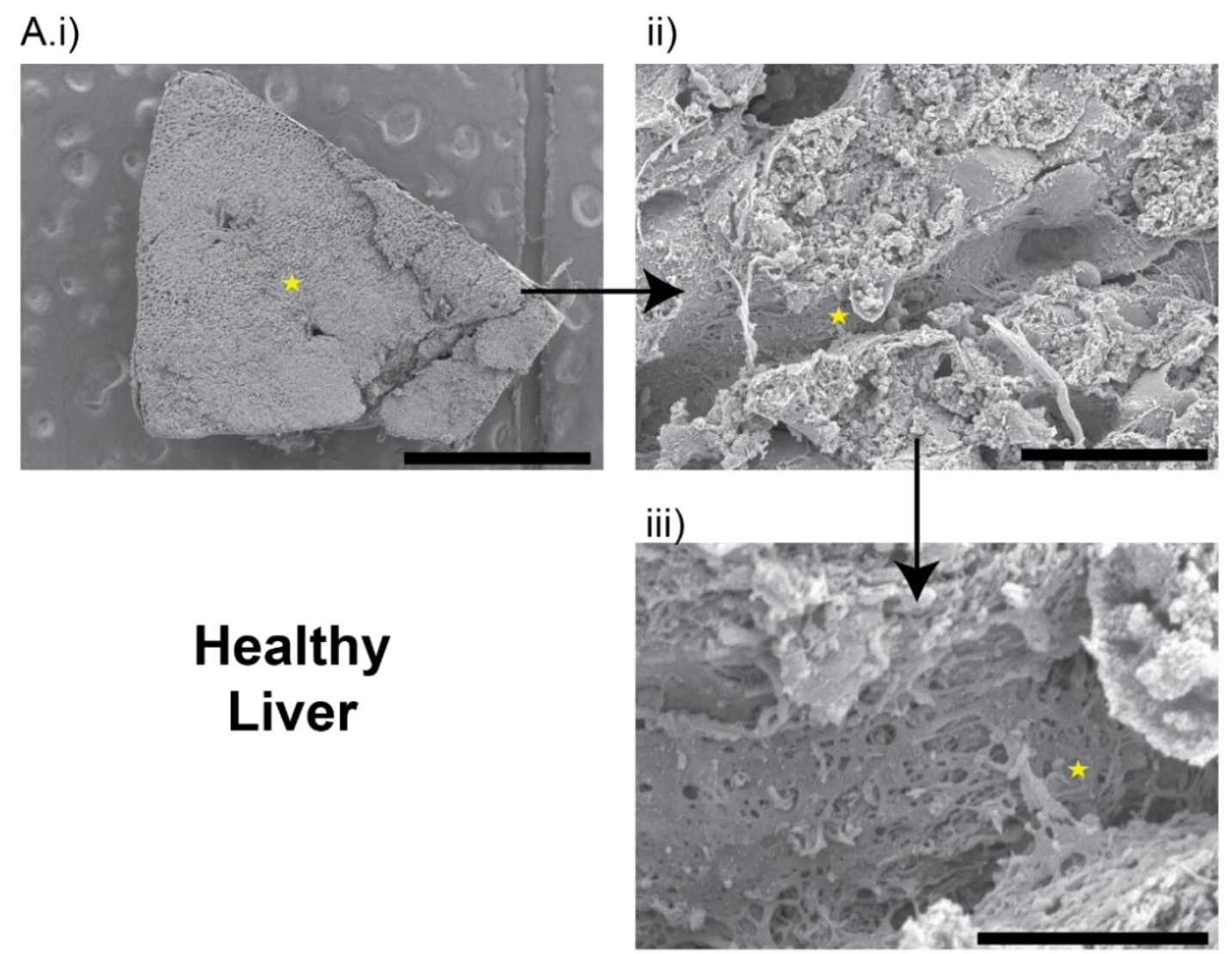

B.i)

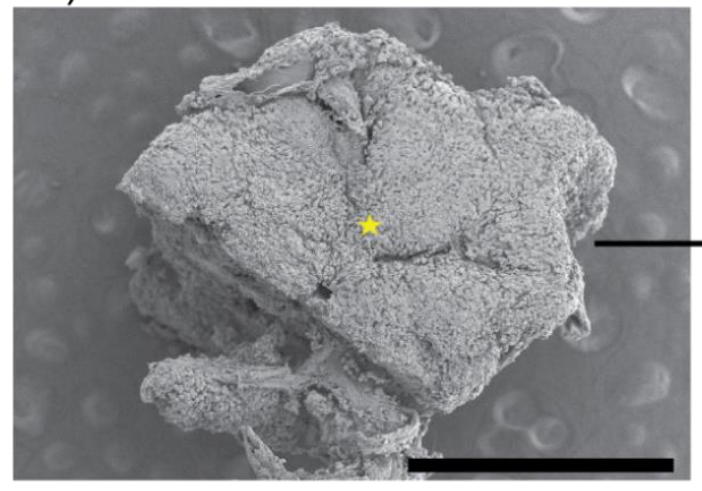

ii)

HCC

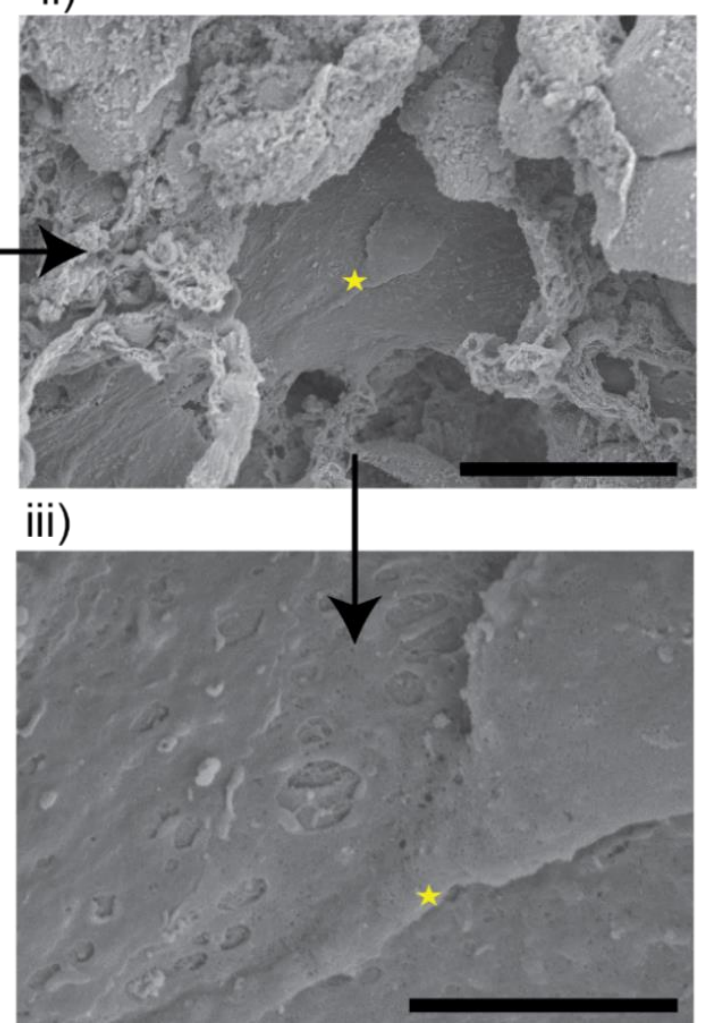

Figure S6: Scanning electron microscopy of healthy and WHV-chronically infected woodchuck livers (Supports Figure 5). (A) Healthy liver and (B) HCC-bearing liver. Point of focus (yellow dot) in A.i and B.i represent the position at which the subsequent photos A.ii-iii and B.ii-iii were magnified. Scale bars for A.i-iii represent $1 \mathrm{~mm}, 20 \mu \mathrm{m}$ and $5 \mu \mathrm{m}$, respectively. Scale bars for B.i-iii are the same as in A.i-iii. 


\section{A i)}

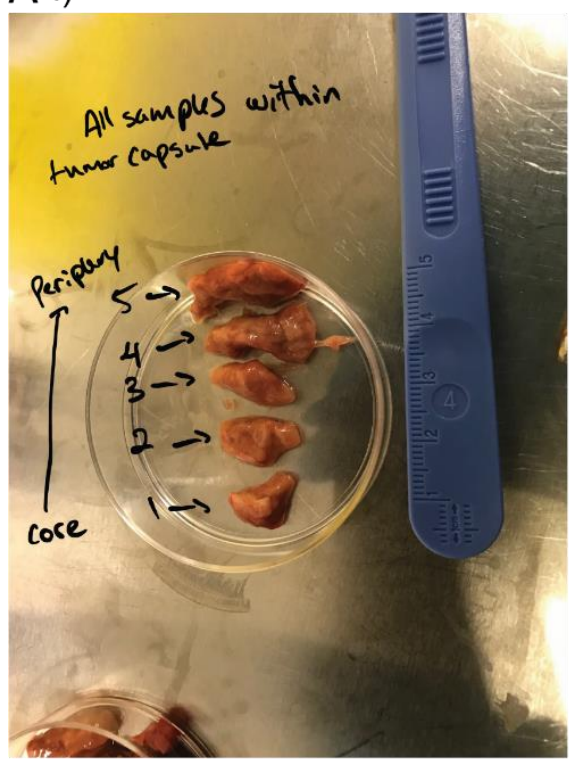

$\mathrm{Bi}$ )

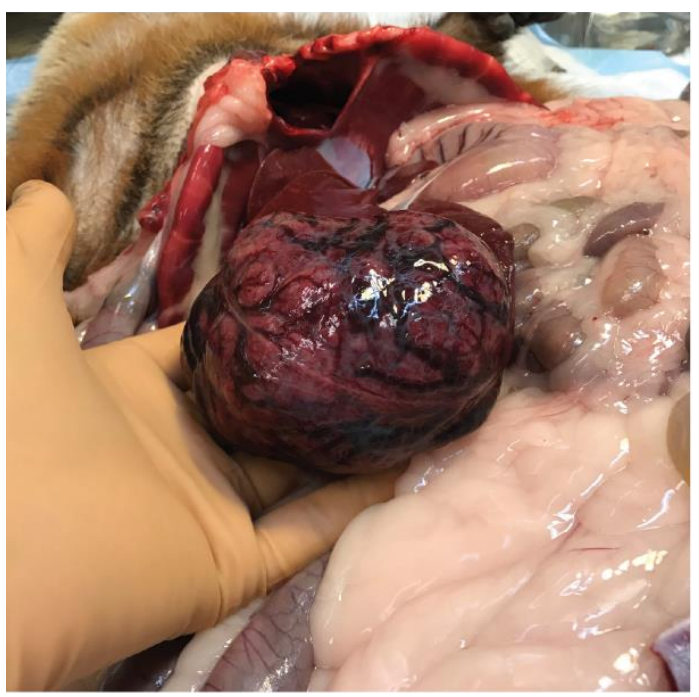

ii)

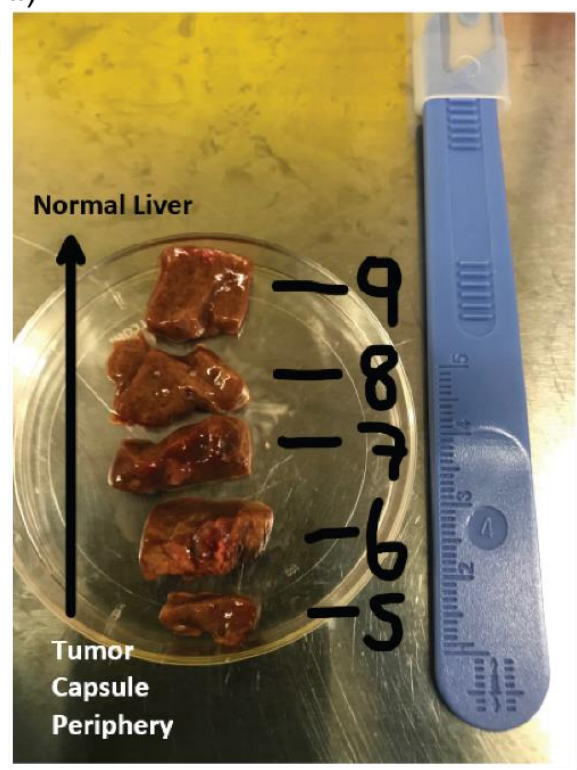

ii)

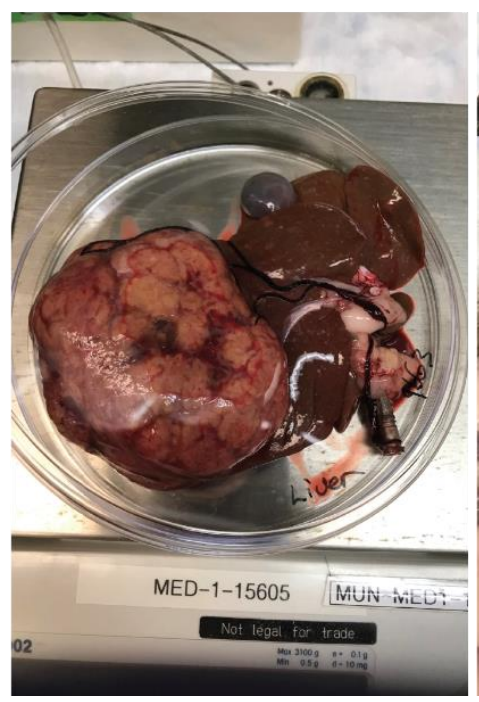

iii)

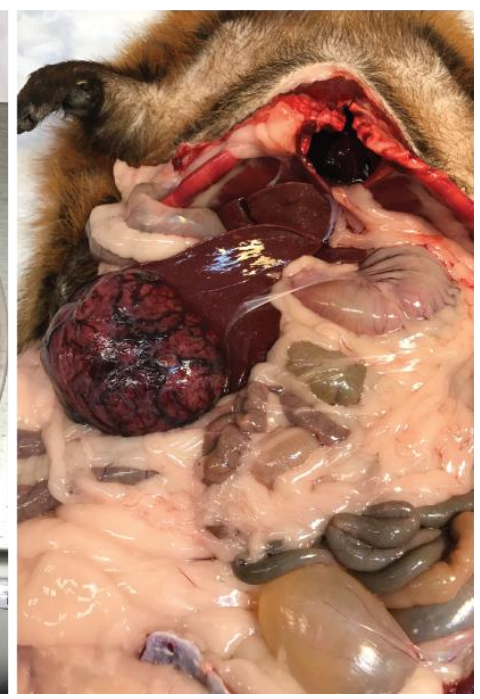

Figure S7: Sectioning of woodchuck HCC for analysis of NP distribution and overall view of a large HCC tumor in woodchuck chronically infected with WHV (Supports Figure 5). (A) Corresponding diagram to Figure 5A.i. where the numerical values denote the position of tumor or tumoruninvolved tissue taken for ICP-MS analysis. Increasing numerical value indicates increasing distance away from the tumor core. (B) Woodchuck HCC at autopsy. Photos taken at $12 \mathrm{~h}$ p.i. of 60-nm gold NPs. 

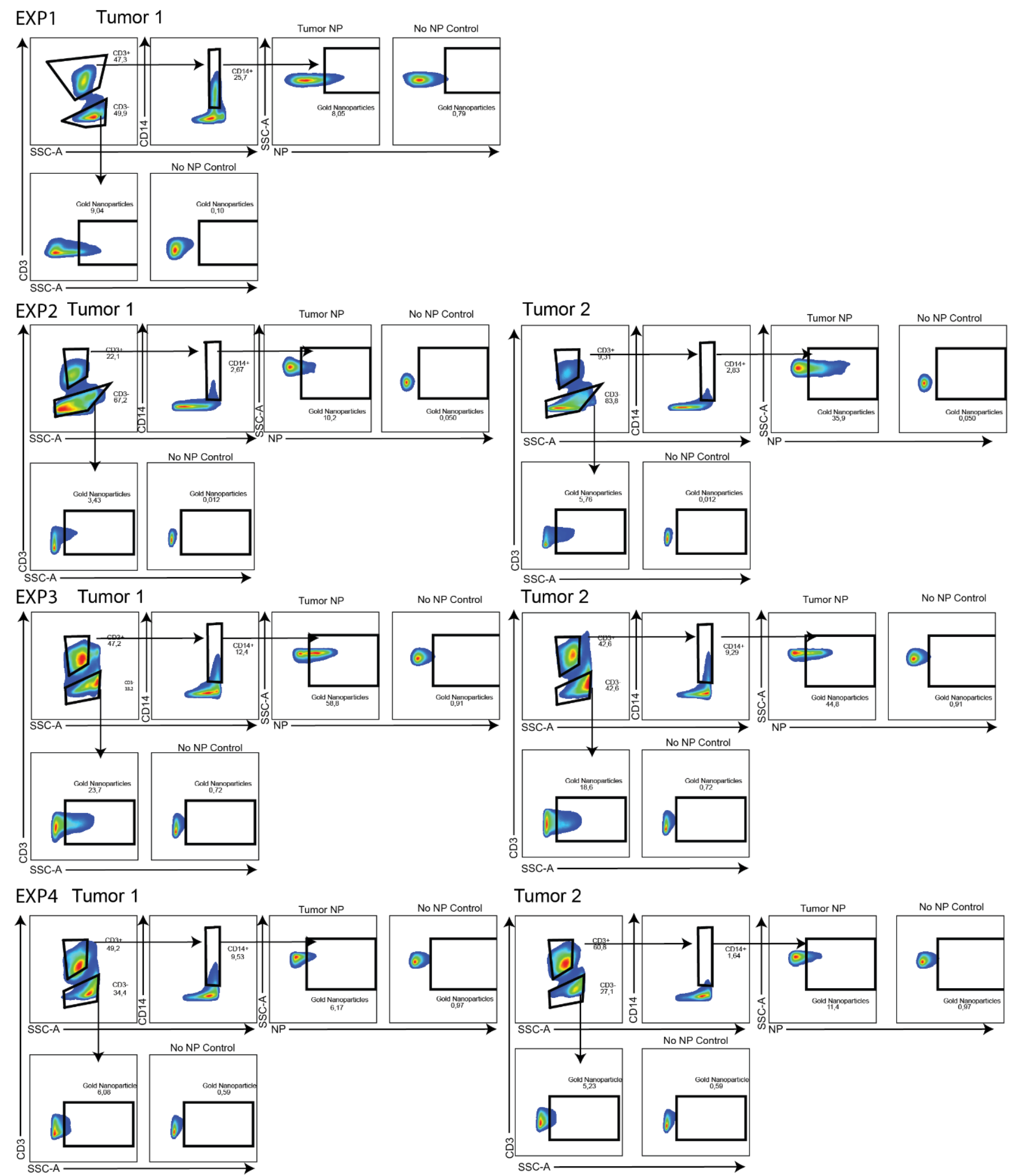

Figure S8: Gating strategy of all $12 \mathrm{~h}$ p.i. in vivo NP uptake experiments in tumour (Supports Figure 5). Flow cytometry gating strategy of the NP uptake by $\mathrm{CD}^{-}$cells and $\mathrm{CD} 3{ }^{-} \mathrm{CD} 14^{+}$cells derived from HCC tumors of WHV-infected woodchucks. This figure along with Figure 3A supports the data shown in Figure 3Biv-v and 3Civ-v by providing the general gating strategy used for analysis. This figure also supports Figure 5 by illustrating the gating strategy and actual values for percentages of the NPs uptake by tumor cells. 

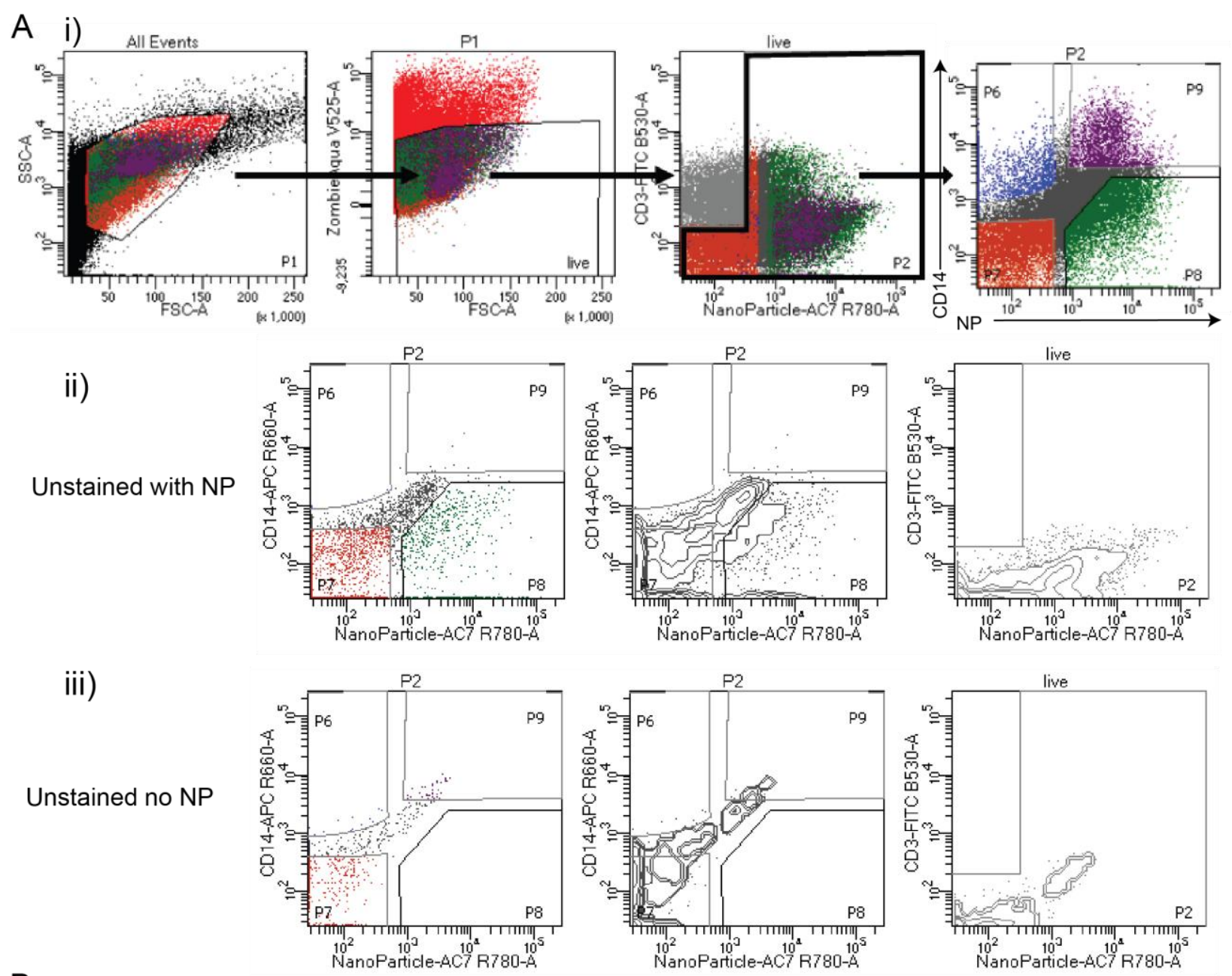

$\mathrm{B}$

\begin{tabular}{|l|l|l|l|}
\hline $\begin{array}{l}\text { CD14+ NP- vs CD14- } \\
\text { NP- }\end{array}$ & $\begin{array}{l}\text { CD14+ NP- vs CD14- } \\
\text { NP+ }\end{array}$ & $\begin{array}{l}\text { CD14- NP- vs CD14+ } \\
\text { NP- }\end{array}$ & $\begin{array}{l}\text { CD14- NP+ vs CD14+ } \\
\text { NP+ }\end{array}$ \\
\hline 3.046985784 & 1.210306168 & -2.65397938 & -0.8172975 \\
\hline
\end{tabular}

Figure S9: Gating strategy for cell sorting experiments (Supports Figure 6). (A) Representative flow cytometry plots of total liver homogenate stained with CD14, CD3 and with viability dye. FACS sorting of four cell populations excluding CD3 ${ }^{-} \mathrm{NP}^{-}$cells, as shown in gates $\mathrm{P} 6\left(\mathrm{CD} 14^{+} \mathrm{NP}^{-}\right.$cells), $\mathrm{P} 7\left(\mathrm{CD} 14{ }^{-} \mathrm{NP}^{-}\right.$ ), P8 (CD14-NP $\left.{ }^{+}\right)$, and $\mathrm{P} 9\left(\mathrm{CD}_{14}{ }^{+} \mathrm{NP}^{+}\right)$. RNA-seq was then performed on each population. ii) Gating control using unstained woodchuck liver from the same NP-injected animal. iii) Gating control for unstained woodchuck liver cells from an animal not injected with NPs. (B) Relative log2-fold change of CD14 transcript measured by RNA-sequencing between different FACS-sorted cell populations. 
A

\begin{tabular}{|c|c|c|c|c|}
\hline Experiment & Weight (kg) & $\underline{\text { Sex }}$ & Status & Tumor Size \\
\hline \multirow[t]{2}{*}{1} & 4.15 & $\mathrm{M}$ & Healthy & $\mathrm{N} / \mathrm{A}$ \\
\hline & 5.43 & $\mathrm{~F}$ & WHV+ & Tumor $\mathrm{A}-8 \mathrm{~cm} \times 7 \mathrm{~cm}$ \\
\hline \multirow[t]{2}{*}{2} & 4.59 & M & Healthy & N/A \\
\hline & 4.73 & M & WHV+ & 4 Tumors - 2 large, 2 small \\
\hline 3 & 5.29 & M & WHV+ & $\begin{array}{c}\text { Tumor A - } 6 \mathrm{~cm} \times 5 \mathrm{~cm} / \text { Tumor B }-3.5 \times 2.5 / \text { Tumor C - } \\
\text { Smallest, Inside lobe }\end{array}$ \\
\hline \multirow[t]{2}{*}{4} & 4.75 & M & Healthy & $\mathrm{N} / \mathrm{A}$ \\
\hline & 2.37 & M & WHV+ & Tumor A $-4.5 \mathrm{~cm} \times 3.5 \mathrm{~cm} /$ Tumor B- $2.1 \mathrm{~cm} \times 2 \mathrm{~cm}$ \\
\hline \multirow[t]{3}{*}{5} & 6.55 & $\mathrm{~F}$ & Healthy & N/A \\
\hline & 3.1 & M & WHV+ & 1 large $-3.5 \mathrm{~cm} \times 4.5 \mathrm{~cm}$ \\
\hline & 4.37 & $\mathrm{~F}$ & WHV+ & $3.0 \mathrm{~cm} \times 2.5 \mathrm{~cm}$ with many small nodules \\
\hline
\end{tabular}

B

\begin{tabular}{|c|c|c|c|c|c|c|c|c|c|c|c|c|c|c|c|c|c|c|c|c|}
\hline \multirow{3}{*}{\begin{tabular}{|l} 
Experiment: \\
Timepoint: \\
Status:
\end{tabular}} & \multicolumn{4}{|c|}{ EXP 1 } & \multicolumn{4}{|c|}{ EXP 2 } & \multicolumn{2}{|c|}{ EXP 3} & \multicolumn{4}{|c|}{ EXP 4} & \multicolumn{6}{|c|}{ EXP 5} \\
\hline & \multicolumn{2}{|c|}{$\mathrm{T}=0$} & \multicolumn{2}{|c|}{$\mathrm{T}=12 \mathrm{~h}$} & \multicolumn{2}{|c|}{$\mathrm{T}=0$} & \multicolumn{2}{|c|}{$\mathrm{T}=12 \mathrm{~h}$} & \multirow{2}{*}{\begin{tabular}{|c|}
$\mathrm{T}=0$ \\
$\mathrm{WHV}+$ \\
\end{tabular}} & \multirow{2}{*}{$\begin{array}{l}\mathrm{T}=12 \mathrm{~h} \\
\mathrm{WHV}+\end{array}$} & \multicolumn{2}{|c|}{$\mathrm{T}=0$} & \multicolumn{2}{|c|}{$T=12 \mathrm{~h}$} & \multicolumn{3}{|c|}{$T=0$} & \multicolumn{3}{|c|}{$\mathrm{T}=48 \mathrm{~h}$} \\
\hline & Healthy & WHV+ & Healthy & WHV+ & Healthy & WHV+ & Healthy & WHV+ & & & Healthy & WHV+ & Healthy & WHV+ & Healthy & WHV+1 & WHV+2 & Healthy & $\mathrm{WHV}+1$ & $W H V+2$ \\
\hline Weight (kg) & 4.16 & 5.43 & & & \begin{tabular}{|l|}
4.59 \\
\end{tabular} & 4.73 & & & 5.3 & & 4.75 & 2.37 & & & \begin{tabular}{|l|}
6.55 \\
\end{tabular} & 3.1 & 4.37 & & & \\
\hline \multicolumn{21}{|l|}{ HEMATOLOGY } \\
\hline Hematocrit (\%) & 47.5 & 38.8 & 39.6 & 33.7 & 42.1 & 37.6 & 40.7 & 33.7 & 44.3 & 36.7 & 39.6 & 40.6 & 33.9 & 36.7 & 50.3 & 52 & 61.8 & 45.5 & 46.4 & 55.8 \\
\hline $\begin{array}{l}\text { Total white blood } \\
\text { cell count }\left(10^{9} / \mathrm{L}\right)\end{array}$ & 11.1 & 16.1 & 11.4 & 13.2 & 17.2 & 18.1 & 19.1 & 7.8 & 13 & 8 & 11.7 & 16 & 18.8 & 10.1 & 5.2 & 10.3 & 50.6 & 14.4 & 11.9 & 31.6 \\
\hline $\begin{array}{l}\text { \% granulocytes } \\
(\%)\end{array}$ & 67 & 75 & 62 & 89 & 66 & 77 & 64 & 59 & 62 & 84 & 66 & 62 & 59 & 50 & 77 & 56 & 68 & 89 & 90 & 89 \\
\hline $\begin{array}{l}\text { \% Lymphocytes/ } \\
\text { monocytes }\end{array}$ & 33 & 25 & 38 & 11 & 34 & 23 & 36 & 41 & 38 & 16 & 34 & 38 & 41 & 50 & 23 & 44 & 32 & 11 & 10 & 11 \\
\hline Hemoglobin ( $\mathrm{g} / \mathrm{dL}$ ) & 15.4 & 11.7 & 13.5 & 11.9 & 14.3 & 12.5 & 14.4 & 11.1 & 13.2 & 12.9 & 13.3 & 13.4 & 11.9 & 13 & 18.5 & 15.8 & 18.5 & 16.4 & 15.7 & 19.6 \\
\hline $\begin{array}{l}\text { Platelet count } \\
\left(10^{9} / \mathrm{L}\right)\end{array}$ & 310 & 808 & 232 & $530^{*}$ & 361 & 581 & 362 & 280 & 878 & 181 & 283 & 358 & 60 & 184 & 246 & 554 & 473 & 25 & 16 & 145 \\
\hline $\begin{array}{l}\text { Total granulocytes } \\
\left(10^{9} / \mathrm{L}\right)\end{array}$ & 7.4 & 12.1 & 7.1 & 11.8 & 11.3 & 14 & 12.2 & 4.6 & 8.1 & 6.7 & 7.7 & 9.9 & 11 & 5 & 4 & 5.8 & 34.4 & 12.8 & 10.7 & 28.1 \\
\hline $\begin{array}{l}\text { Total lymphocyte/ } \\
\text { monocyte count } \\
\left(10^{9} / \mathrm{L}\right)\end{array}$ & 3.7 & 4 & 4.3 & 1.4 & 5.9 & 4.1 & 6.9 & 3.2 & 4.9 & 1.3 & 4 & 6.1 & 7.8 & 5.1 & 1.2 & 4.5 & 16.2 & 1.6 & 1.2 & 3.5 \\
\hline \multicolumn{21}{|l|}{ BIOCHEMISTRY } \\
\hline ALT (U/L) & $<10$ & 22 & & & NA & 26 & & & 28 & 54 & 48 & 42 & 19 & 58 & $<10$ & $<10$ & 12 & $<10$ & 22 & $<10$ \\
\hline GGT (U/L & 0 & 183 & & & 0 & 90 & & & 484 & NA & 3 & 61 & NA & NA & 0 & 150 & 178 & 0 & 137 & 99 \\
\hline AST (U/L) & NA & NA & & & 80 & 135 & & & 44 & 92 & NA & NA & NA & NA & 18 & 13 & 58 & 121 & 138 & 267 \\
\hline TBIL umo/L & NA & NA & & & $<2$ & $<2$ & & & $<2$ & 46 & $<2$ & $<2$ & 40 & 36 & NA & NA & NA & NA & NA & NA \\
\hline
\end{tabular}

*tested at plasma dilution 1:5 / NA, not available

Figure S10: Characteristics of woodchucks investigated. (A) Table showing WHV infection status, and general animal and HCC tumor characteristics. Animals in experiments (EXP) 1-4 were examined at 12 hours after injection with NPs, while those in experiment 5 were examined at 48 hours post NPs administration. (B) The results of selected hematological and biochemical evaluations of blood or plasma samples obtained from woodchucks investigated in this study. Samples we collected prior to injection with NPs (i.e., time $0, \mathrm{~T}=0$ ) and at autopsy (i.e., time 12 or $48 \mathrm{~h}$ p.i. with $\mathrm{NPs}, \mathrm{T}=12$ or $\mathrm{T}=48$ ). Alt, alanine aminotransferase; GGT, gamma-glutamyltransferase; Ast, aspartate aminotransferase, and TBIL, total bilirubin. 
Supplemental Video 1: Live confocal microscopy imagining: Video is showing magnetically sorted $\mathrm{CD} 14^{+}$cells from dissociated non-tumor liver tissue of a WHV-chronically infected animal treated with 60-nm gold nanoparticles. Total z-stack range is $19 \mu \mathrm{m}$. Nanoparticles (red), actin (green), nucleus (blue).

Supplemental Information 1: Quality control for RNA-sequencing experiments: Quality control information for the four FACS sorted cell populations $\left(\mathrm{CD} 14^{+} \mathrm{NP}^{-}, \mathrm{CD}^{-} 4^{-} \mathrm{NP}^{-}, \mathrm{CD}^{-} 4^{-} \mathrm{NP}^{+}, \mathrm{CD}^{+} 4^{+}\right.$ $\mathrm{NP}^{+}$) that were transcriptionally profiled. These four cell populations were obtained from dissociated liver tissue from the animal used in experiment 3 (EXP3). Please see Figure S10 for additional details regarding animal characteristics in each experiment. Counts per million $=\mathrm{CPM}$

Supplemental Table 1: Amino acid sequence alignment between woodchuck and human: Table is showing the degree of homology between each query protein (GCA_901343595.1_MONAX5_protein.faa) and subject protein (GCF_000001405.39_GRCh38.p13_protein.faa). "Single hit" is a filtered list such that only the segment with the greatest alignment to the subject for each query is returned.

Supplemental Table 2: Gene expression values for FACS sorted cell populations: Values are expressed as log2-change in comparison to the indicated cell population listed in the first row. 